$\xi=-$ 国

\title{
Performance of Hospital Information System in Malaysian Public Hospital: a Review
}

\author{
Revita Desi Hertin ${ }^{1}$, Omar Ismael Al-Sanjary ${ }^{2 *}$ \\ ${ }^{I}$ Faculty of School of Graduates Studies, Management and Science University, Malaysia \\ ${ }^{2}$ Faculty of Information Science and Engineering, Management and Science University, Malaysia \\ *Corresponding author E-mail: omar_ismael@msu.edu.my
}

\begin{abstract}
This paper presents an extensive literature review of Hospital Information System (HIS) in public hospital in Malaysia. This paper aims to deliver information (guideline) about the importance and benefits of HIS so that can help government to enhance the standard of healthcare quality. Accordingly, the Malaysian Government Ministry of Health (MoH) has presented three groups of HIS such as Basic Hospital Information System (BHIS), Intermediate Hospital Information System (IHIS), and Total Hospital Information System (THIS) amongst Malaysian government owned (public) hospitals. In Malaysia, there are 138 public hospitals but at this time only 21 hospitals implementing HIS. In this paper, researcher explains the three groups of HIS (THIS, BHIS, IHIS), the benefits, the challenges, the frameworks, also the current issues of HIS.
\end{abstract}

Keywords: Hospital; Hospital Information System; Health Information System.

\section{Introduction}

The Malaysia government applied HIS nationwide to expand the usefulness of technology to enhance healthcare delivery, however, not much-known about the advantages and issues of HIS adoption in each intuition. HIS implementation aims to enhance healthcare quality, boost productivity and enable easy data obtainment and data recording. HIS can also decrease errors in comparison to the manual system and increase communication among the staffs.

The HIS is characterized as a coordinated electronic framework that gather, store, recover and show general patients' information and data, for example, history of patients' data, consequences of research centre test, judgments, charging and others related clinic's strategies which are utilized as a part of a few offices inside healing centres [1, 2]. Malaysian Ministry of Health started to exhibit HIS in 1999 to cover both clinical and non-clinical data system. From that point forward doctor's facilities have been managed difficulties to accomplish the targets of its presentation.

HIS can enable simple access to patient's information, settle on clinical choice help, keep report information on medicinal services quality and security, and enhance request and receipt of lab tests and in addition demonstrative pictures. To put it plainly, it is also viable than paper-based system in a few approaches. Despite, it is not a simple work to carry out the HIS in hospitals where a considerable measure of difficulties is confronted, particularly as far as hierarchical variables, since clinic is a large association with complex authoritative structures [3].

This paper explains about HIS performance in Malaysian government-owned Hospitals and HIS groups. HIS performs a main role in modern healthcare. The benefits of HIS including to share information and date, as easier of transaction or work processes [4], simple way to access to patients' information and organized data [5], diminishes translation blunders and decreases duplication of data passages and enhanced checking of medication utilization, and investigation of viability [6]. In this manner, a great comprehension of the HIS is required. Even though the HIS has so many benefits to the Hospital but there are problems the government facing while implementing HIS, not only for funding but from the hospital itself such as the user acceptance, user skill and how to change their perspective that with HIS Hospital will have a better service.

This paper aims to give information about the importance and the benefits of HIS so that in the future can help government to enhance the quality of healthcare in Malaysia, especially to enhance the quality of service in Malaysian public hospital since so many people depends on them, not only because they have it each province but also for the affordable for nationwide.

\section{Related Works}

As indicated to Abdul Hamid, the arranging of HIS adoption started in 1993 which began under sixth Malaysian Plan (MP)) named as THIS in Hospital Selayang. At that point, in 1996, telehealth project was propelled on 1996, 1st August. Besides, HIS execution occurred alongside physical development under the seventh MP. Now, in total138 public hospitals in Malaysia, there are only 21 hospitals are implementing the system [7-9]. Along with this line, the stage of HIS adoption and performance is still in ground level [7].

Hospitals need to adopt HIS to enhance their operations and administration. Disregarding their hugeness, just $15.2 \%$ of Malaysian Public Hospitals actualized the framework through THIS, IHIS and BHIS aggregate that demonstrates low gathering level of HIS in Malaysia [5]. 


\subsection{Hospital Information System in Malaysian Public Hospital}

The performance of HIS in Malaysian government-owned (public) Hospitals are separated to three groups, they are Basic Hospital Information System (BHIS), Intermediate Hospital Information System (IHIS) and Total Hospital Information System (THIS). Now, there are 11 public hospitals indicate for THIS, 2 public hospitals indicate for IHIS and 8 hospitals indicate for BHIS in Malaysia [7, 10, 11]. It describes all of 138 only 21 hospitals adopted HIS, or only $15.2 \%$ of government-owned hospitals implemented the HIS in Malaysia. This group of HIS is built upon the size of the hospital and total beds they have [7].

Total Hospital Information System (THIS): Hospital Putrajaya, Hospital Ampang, Hospital Pandan, Hospital Selayang, Hospital Alor Setar, Hospital Sg. Buloh, Hospital Sultanah Zahirah, Hospital Serdang, Hospital Bintulu, Hospital Sungai Petani, Hospital Haji Ahmad Shah. Intermediate Hospital Information System (IHIS): Hospital Lahad Datu, and Hospital Keningau. For Basic Hospital Information System (BHIS): Hospital Kuala Batas, Hospital Setiu, Hospital Pekan, Hospital Pitas, Hospital Kunak, Hospital Kuala Penyu, Hospital Port Dickson, and Hospital Tuanku Ja'afar [7].

Table 1: Hospital Categories [7]

\begin{tabular}{|c|c|c|}
\hline THIS & IHIS & BHIS \\
\hline Hospital Putrajaya & Hospital Ld Datu & Hospital Kuala Batas \\
\hline Hospital Ampang & $\begin{array}{c}\text { Hospital Ken- } \\
\text { ingau }\end{array}$ & Hospital Setiu \\
\hline Hospital Pandan & & Hospital Pekan \\
\hline Hospital Selayang & & Hospital Pekas \\
\hline Hospital Alor Setar & & Hospital Kunak \\
\hline Hospital Sg. Buloh & & Hospital Kuala Penyu \\
\hline Hospital Sultanah Zahirah & & $\begin{array}{c}\text { Hospital Tuanku } \\
\text { Ja'afar }\end{array}$ \\
\hline Hospital Serdang & & \\
\hline Hospital Bintulu & & \\
\hline Hospital Sg. Petani & & \\
\hline Hospital Hj Ahmad Shah & & \\
\hline
\end{tabular}

All kind of HIS groups is classified by the components they have of Information System (IS) being executed in the hospitals. Furthermore, paperless hospitals are mentioned for Total information system since they have all parts of HIS components. But, IHIS and BHIS still use both manual and electronic systems. This is on the grounds that hospital of BHIS and IHIS's hospitals embraced just with a few types of IS. Accordingly, a previous study discovered the aspects that influencing the Malaysian Public Hospitals of HIS adoption are Organizational, Technological, Human, and Environmental [12].

From Figure 1, there are 3 types of HIS groups by the components they have; for BHIS, it only has Financial Management System and Clinical Information System; for IHIS, it's combination of BHIS and Laboratory Information System and Pharmacy Information System; and for THIS, it's combination of IHIS, Picture Archiving Communication System, Admin, Inventory, and Personal Information system [14].

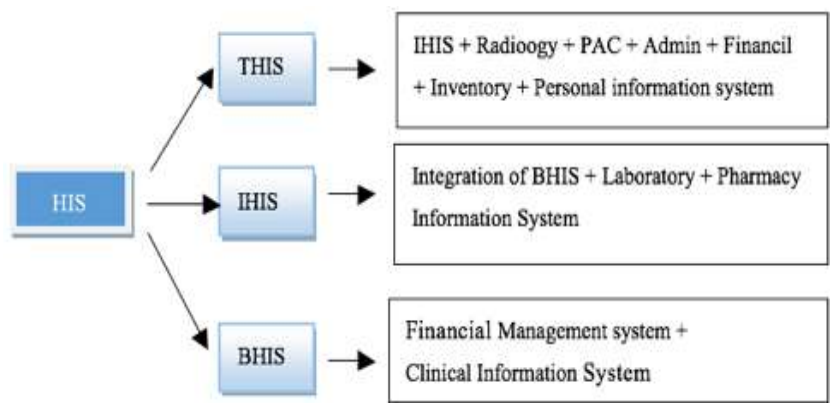

Fig. 1: HIS Categories by the components [13].

\subsection{HIS Components}

Table 2 demonstrates the components of HIS by their specialties and clients. A Clinical Information System (CIS) is a PC based system that is intended for gathering, putting away, controlling and making accessible clinical data essential to the human services conveyance process. Normally, it has been utilized as a part of clinical office (specialists and medical attendants). Besides, a Financial Information Systems (FIS) alluded to as PC system that deals with the business parts of a clinic and utilized by accountants. Besides, a Laboratory Information System (LIS) is a PC data system that oversees lab data for all the lab discipline, for example, clinical science, hematology, and microbiology. Other than that, Nursing Information Systems (NIS) is a PC system that oversees clinical information from an assortment of medicinal services conditions and made accessible in an auspicious and precise design to help nurture in enhancing persistent care which is utilized as a part of wards by specialists and attendants.

A Pharmacy Information System (PIS) is a perplexing PC system that has been intended to address the issues of a drug store office which is utilized by the pharmacist. Moreover, a Picture Archiving Communication System (PACS) is a free term to depict an arrangement of frameworks that encourage the chronicling, preparing and survey of computerized radiological pictures and their related data and utilized as a part of $\mathrm{x}$-beam and imaging office by Imaging Officers. Finally, a radiology data framework (RIS) is a PC framework that helps radiology benefits in the putting away, control and recovering of data [16].

Table 2: Components of Hospital Information System (HIS) [9]

\begin{tabular}{|c|c|c|}
\hline Component & Department & User \\
\hline Financial Information System (FIS) & Financial & Accountants \\
\hline Clinical Information System (CIS) & Clinical & $\begin{array}{c}\text { Doctors and } \\
\text { nurses }\end{array}$ \\
\hline $\begin{array}{c}\text { Nursing Information System (NIS) } \\
\text { Doctors }\end{array}$ \\
\hline $\begin{array}{c}\text { Laboratory Information Systems } \\
\text { (LIS) }\end{array}$ & Laboratory & Lab officers \\
\hline Radiology Information System (RIS) & imaging & Radiologist \\
\hline $\begin{array}{c}\text { Picture Archiving Communication } \\
\text { System (PACS) }\end{array}$ & Imaging & Imaging Officer \\
\hline Pharmacy Information System (PIS) & Pharmacy & Pharmacist \\
\hline
\end{tabular}

\section{HIS Framework for Analyzing HIS Imple- mentation}

The individual and hierarchical level have broadly been examined regarding the IT appropriation. In any case, a considerable lot of the IT reception inquires about have concentrated on the individual level by clarifying what impacts their behavioral aim to utilize a specific innovation [15]. Here is the list of Framework of His Adoption.

Among the IS models, Delone and McLean is a winning show is a standout amongst the most broadly referred to. The researcher uses Delone and McLean model to analyze the implementation of HIS whether it succeeds or not. TAM is the one to measure the acceptance level of HIS. 
Table 3: HIS Framework

\begin{tabular}{|c|c|c|}
\hline No. & Framework & Explanation \\
\hline 1 & TOE Framework & $\begin{array}{l}\text { In the TOE structure, the components of and the hindrances to HIS reception are arranged into three estimations, } \\
\text { which are Technology, Organization, and Environment. In institutional speculation, the environment estimation of } \\
\text { TOE has been affected because of the intricate idea of social insurance including numerous partners, which apply } \\
\text { diverse institutional weight. Another estimation of human has been incorporated from HOT-fit as a supplement into } \\
\text { the TOE to be more expansive [10]. }\end{array}$ \\
\hline 2 & $\begin{array}{l}\text { Importance-performance } \\
\text { analysis (IPA) framework } \\
\qquad[16,17]\end{array}$ & $\begin{array}{l}\text { The importance-performance analysis (IPA) technique was first illustrated in the marketing writing [16] and has since } \\
\text { been connected in a wide assortment of item and administration settings as a reason for setting administration needs } \\
\text { and deciding how rare assets may best be assigned [17]. IPA is essentially a quantitative method for mentioning } \\
\text { analytic objective facts of client encounters by surveying singular fulfillment along an arrangement of characteristics } \\
\text { (for our situation, framework qualities) and afterward organizing change endeavors as indicated by each ascribes } \\
\text { relative significance to clients. }\end{array}$ \\
\hline 3 & $\begin{array}{l}\text { Health Level Seven } \\
\text { (HL7) [18] }\end{array}$ & $\begin{array}{l}\text { Health Level Seven (HL7) is IN American National Standards Institute (ANSI) certify Standards Developing Organi- } \\
\text { zations, working in the healthcare field around the world. ("Level Seven" alludes to the most abnormal amount of the } \\
\text { International Standards Organization's (ISO) correspondences demonstrate for Open Systems Interconnection (OSI) } \\
\text { - the application level.) [18]. Hospitals and other healthcare provider organizations typically have many different } \\
\text { computer systems used for everything from billing records to patient tracking. }\end{array}$ \\
\hline 4 & MCDM model [15] & $\begin{array}{l}\text { Comprises of the Decision-Making Trial and Evaluation Laboratory (DEMATEL) and Analytic Network Processes } \\
\text { (ANP) to assess and discover the significance level of the decided components for HIS selection in Malaysia. In such } \\
\text { manner, DEMATEL is connected to develop interrelationship among selection factors in the incorporated model [14]. }\end{array}$ \\
\hline 5 & $\begin{array}{l}\text { Human-Organization- } \\
\text { Technology (HOT) fit } \\
\text { model [19] }\end{array}$ & $\begin{array}{l}\text { This proposed framework related with an arrangement of complete measurements and estimation of the wellbeing } \\
\text { data framework. They recommend that the more fit between innovation, human, and association, the more capable of } \\
\text { the wellbeing data framework can be acknowledged [15]. }\end{array}$ \\
\hline 6 & $\begin{array}{c}\text { 3LGM2 (Three-layer } \\
\text { Graph-based meta-model) } \\
{[20]}\end{array}$ & $\begin{array}{l}\text { 3LGM2 (Three-layer Graph-based meta-model) is an organized and in a few nations effectively approved approach } \\
\text { for displaying and investigating HISs.'3LGM2 consolidates a useful meta show with specialized meta models and is } \\
\text { spoken to utilizing the Unified Modeling Language (UML)' [16]. }\end{array}$ \\
\hline 7 & $\begin{array}{l}\text { Delone and McLean } \\
\text { model }[21,22]\end{array}$ & $\begin{array}{l}\text { This model measures the successful appropriation of data framework in light of three criteria, in particular; service } \\
\text { quality, system quality, and information quality. Data quality is the attractive attributes of the framework yields, as it } \\
\text { identifies with significance, precision, succinctness, fulfillment, justifiable, cash, opportuneness, and ease of use [25, } \\
\text { 26]. }\end{array}$ \\
\hline 8 & $\begin{array}{l}\text { Theory Acceptance Mod- } \\
\text { el (TAM) [23] }\end{array}$ & $\begin{array}{l}\text { An information systems theory that models how clients and users come to acknowledge (accept) and utilize an inno- } \\
\text { vation. The model recommends that when clients are given another innovation, various elements impact their choice } \\
\text { about how and when they will utilize it, TAM is a model has been tested in healthcare to identify user acceptance } \\
\text { factors and the relationships between factors [27]. }\end{array}$ \\
\hline
\end{tabular}

\section{HIS Benefits to the User}

HIS adoption advantages including to enhance healthcare value, boost productivity [24] and easier data obtainment and data collecting [25]. HIS can also minimize errors in comparison to a manual system [26] and better communication among the staff [27]. Nowadays, patients technologically understand because of the faster innovations and growth in medical term, and the health disparity space is retiring [12]. Classification, information produced in the HIS can be of numerous kinds such as identification data, clinical requests, lab results, administrative information and so forth. It is imperative to keep up the privacy of this information in the great enthusiasm of both the patient and the healthcare supplier [26].

Security of information, the safe administration of patient and other information utilizing HIS strongly affects nature of patient care, understanding rights and medicinal services experts and their work rehearse [26].

\subsection{Staffs}

In staff detail, there is the detail data of the hospital staff. The staff module contains the data about the specialist, nurse and another individual who work in the hospital like peons, accounts, servers, sweepers and so forth. Here, we can adjust the rundown on the off chance that we need to refresh the present information of the healing center. The aggregate data about the staff we will get in the staff show. The staff module is principle key of the healing center administration venture [28]. Securing the privacy of health and other administrative information in HIS is vital to guarantee that person's entitlement to protection is being ensured. The decrease of copy work, a decent healing HIS ought to lessen the duplication of data passages and decrease the end user time in archiving patients and administrative information [29].

\subsection{Patients}

Patient satisfaction is hugely considered as an integral part of the quality of care. Furthermore, patient satisfaction is identified as an important dimension for assessing the quality of healthcare services. Lately, for developing countries, impacted intensely by discoveries of developing countries are progressively keen on assessing the healthcare service quality [4].

In the electronic information record, we can get to the information and recover the information speedier as the contrast with the prior manually written framework. In this module, we can see the subtle elements of the patient record, for example, the concede card shape, release frame, Room change frame, X-beam frame [30]. Here, in the patient module, the whole information is in the electronic information frame where we can see recover the whole information of the patient when he/she enter the pertinent code of the concede card and the information identified with the patient his/her name, address, sexual orientation, cause, referred by, specialist name [31].

New innovation can be an indispensable medicine and HIS is no exemption. Thru definite patient medical records, hospital and clinics approach significantly more data and can recover this data speedier than at any other time [32]. The advancement and mix of PC and medical science has opened the entryways for medicinal authorities and given patients a better quality of service and treatment. There are numerous advantages to utilizing HIS. Using PCs, the Internet, and different restorative databases, doctor and specialists can better figure out how to treat patients all the more successfully [33]. The information recovered by the utilization of HIS gives measurable data that can profoundly affect how medicine is appropriated, medical procedures are performed, and how healing process is followed. It additionally enables healing centers to better track patients' past records so they can be dealt with quicker later on [3]. The utilization of HIS has opened up the entryways for centers to be more equipped for treating patients in a more proficient way and enables these clinics to refine their present procedure to make it more shorten [2]. 


\section{Limitation of HIS in Malaysia}

There are some issues that Malaysia been facing while implementing Hospital Information System in Malaysia such as Limited Financial Sources because HIS is a project under $\mathrm{MoH}$ so $\mathrm{MoH}$ has the full authority about the funding [7], Low Acceptance Level because some of the staff especially those who work more than 20 years and they still use the paper base [34], Low Satisfaction Level such as the data collections or data adjustment sometimes does not work well [28], some issues of technology [34], are for occurrences reciprocal changes and bolster and lacking information exchange. Next to that, interoperability (standard ability of computerized systems to relate and communicate with one another readily) is one of another big challenge to implement the system, and also user skill, lack of users skill for using the system because the staffs have lack of computer and basic IT skills due to the lack of knowledge in IT are the issues of human-related [28].

\section{Conclusion}

The significance of Government-owned (public) hospitals in Malaysia are should have been concern exceptionally to serve the excessively expensive nation. By and large, the usage of the HIS is vital as it gives numerous positive effects to the performance of Government-owned (public) hospital in Malaysia. Consequently, in this technological era, the HIS is should have been connected and implement in numerous different hospitals as it is helpful in enhancing and improving the recording data system in hospitals since now only twenty-one hospitals have adopted HIS. Hence, the HIS may increase the quality and services. Consequently, the HIS usage is important to be enhanced in all Malaysian Public Hospitals later on.

Even though HIS implementation is so important for Malaysia Public Hospital, there are such issues government facing such as limited financial sources, so that not every hospital can afford to implement the HIS, also some issues for the users such as low acceptance level because the longer the staff works for hospital, they like to maintain with the old system, low satisfaction level because sometimes the system just not work properly, and also lack of facilities such as computers and laptop for the users (Hospital staff).

\section{Recommendations}

From the previous study, we know that HIS is very important not only for the staff but also for the patients. Patient's satisfaction is very important, health care quality is so important and needs to improve more. HIS benefits not only for the medical records, security, less error but also for time management in the hospital, waiting time and how they serve more patients in a day. Even though we know HIS's significance, there are also some issue that government facing such funding and also lack of skill of the users of HIS. Knowing the information of HIS, we really hope there is more hospitals will adopt HIS time by time because for now only a few hospitals implemented the HIS. Also, we hope day by day the users will not stop to learn about HIS, so that the user acceptance and user satisfaction of HIS will increase to the health care quality become better than before.

\section{Acknowledgment}

This paper is sponsored by Management and Science University Malaysia and the authors is under scholarship of the university and would like to thank the related peoples that help contributed to the success of this study direct or indirect. In addition, the authors would like to thank Dr. Izzati from University Tun Hussein Onn Malaysia for her help while doing this paper and also thank the anonymous referees for their comments and suggestion.

\section{References}

[1] A. Ismail, A. T. Jamil, A. F. A Rahman, J. M. Abu Bakar, N. Mohd Saad, and H. Saadi, "The implementation of Hospital Information System (HIS) in tertiary hospitals in Malaysia," Malaysian $J$. Public Heal. Med. 2010, 10(2), 16-24, 2010.

[2] N. Azliza, N. Ariffin, A. M. Yunus, and Z. C. Embi, "Improving Electronic Medical Records ( EMRs ) Practices through a Clinical Microsystem in the Malaysian Government Hospitals," Commun. IBIMA, 5, 50-64, 2008.

[3] S. Silow-Carroll, J. N. Edwards, and D. Rodin, "Using electronic health records to improve quality and efficiency: The experiences of leading hospitals.," Issue Brief (Commonw. Fund), 17, 1-40, 2012.

[4] R. K. Sinha, and S. Kurian, "Assessment of end user satisfaction of hospital information system informatic Al Spitalului," Management in Health, 18(3), 26-33, 2014.

[5] N. I. Ismail, and N. H. Abdullah, "An overview of hospital information system (HIS) implementation in Malaysia," Proceedings of the 3rd International Conference on Business and Economic Research, pp. 1176-1182, 2012.

[6] M. Harrison, R. Koppel, and S. Bar-Lev, "Unintended consequences of information technologies in healthcare - An interactive sociothecnical analysis," J. Am. Med. Informatics Assoc. 14, 542-549, 2007.

[7] N. I. Ismail, N. H. Abdullah, A. Shamsudin, and N. A. N. Ariffin, "Implementation differences of Hospital Information System (HIS) in Malaysian public hospitals," Int. J. Soc. Sci. Humanit., 3(2), 115-120, 2013.

[8] A. Ismail, A. T. Jamil, A. F. A. Rahman, J. M. A. Bakar, N. M. Saad, and H. Saadi, "The implementation of Hospital Information System (HIS) in tertiary hospitals in Malaysia: A qualitative study," Malaysian Journal of Public Health Medicine, 10(2), 16-24, 2010.

[9] N. I. Ismail, N. H. Abdullah, and A. Shamsuddin, "Adoption of hospital information system (HIS) in Malaysian public hospitals," Procedia-Social and Behavioral Sciences, 172, 336-343, 2015.

[10] [10]H. Mohd, S. Mastura, and S. Mohamad, "Acceptance model of electronic medical record," J. Adv. Inf. Manag. Stud., 2(1), 75-92, 2005.

[11] “2011_HIS.pdf."

[12] N. Azzah, A. Bakar, and N. Chepa, "Challenges in the implementation of hospital information systems in Malaysian public hospitals," Proceedings of the 6th International Conference on Computing \& Informatics, pp. 636-642, 2017.

[13] M. Yunus, D. Syadia, A. Latiff, S. C. Din, and S. Noorsuriani, "Patient Satisfaction with Access to 1Malaysia Clinic," Procedia Soc. Behav. Sci., 91, 395-402, 2013.

[14] N. I. Ismail, "Development of implementation models for hospital information system (HIS) in Malaysian public hospitals," $\mathrm{PhD}$ thesis, Universiti Tun Hussein Onn Malaysia, 2016.

[15] [15]H. Ahmadi, M. Nilashi, and O. Ibrahim, "Organizational decision to adopt hospital information system: An empirical investigation in the case of Malaysian public hospitals," Int. J. Med. Inform., 84(3), 166-188, 2015.

[16] J. A. Martilla and J. C. James, "Importance-per analysis," Journa of Marketing 41(1), 77-79, 1977.

[17] K. Matzler, M. Fuchs, and A. K. Schubert, "Employee satisfaction: Does Kano's model apply?," Total Qual. Manag. Bus. Excell., 15(9-10), 1179-1198, 2004.

[18] M. Nilashi, H. Ahmadi, A. Ahani, R. Ravangard, and O. Ibrahim, "Determining the importance of Hospital Information System adoption factors using Fuzzy Analytic Network Process (ANP)," Technol. Forecast. Soc. Change, 111, 244-264, 2016.

[19] M. M. Yusof, A. Papazafeiropoulou, R. J. Paul, and L. K. Stergioulas, "Investigating evaluation frameworks for health information systems," Int. J. Med. Inform., 77(6), 377-385, 2008.

[20] A. Winter, B. Brigl, and T. Wendt, "Modeling Hospital Information Systems (Part 1): The Revised Three-layer Graph-based Meta Model 3LGM2," Methods Inf. Med., 42(5), 544-551, 2003.

[21] W. H. Delone and E. R. Mclean, "The DeLone and McLean Model of Information Systems Success," J. Manag. Inf. Syst., 19(4), 9-30, 2003.

[22] I. M. Amin, S. S. Hussein, and W. A. Isa, "Assessing user satisfaction of using hospital information system (HIS) in Malaysia," Proceedings of the International Conference on Social Science and Humanity, pp. 1-4, 2011.

[23] A. K. Yarbrough and T. B. Smith, "Technology acceptance among 
physicians: A new take on TAM," Med. Care Res. Rev., 64(6), 650-672, 2007.

[24] B. Gheorghiu and S. Hagens, "Measuring interoperable EHR adoption and maturity: A Canadian example," BMC Med. Inform. Decis. Mak., 16(1), 1-7, 2016.

[25] L. G. Jensen and C. Bossen, "Factors affecting physicians' use of a dedicated overview interface in an electronic health record: The importance of standard information and standard documentation," Int. J. Med. Inform., 87, 44-53, 2016.

[26] R. El-Kareh, O. Hasan, and G. D. Schiff, "Use of health information technology to reduce diagnostic errors," BMJ Qual. Saf., 22(Suppl 2), 40-51, 2013.

[27] N. I. Ismaill and N. H. Abdullah, "Implementation and acceptance of Hospital Information System," 2013, http://eprints.uthm.edu.my/5792/1/2._Nurul_Izzatty_Ismail.pdf

[28] N. Zakaria and S. A. Mohd Yusof, "Understanding Technology and People Issues in Hospital Information System (HIS) Adoption: Case study of a tertiary hospital in Malaysia," J. Infect. Public Health, 9(6), 774-780, 2016.

[29] J. E. Bailey, "Virtual mentor," Ethics, 12(7), 197-201, 2010.

[30] N. I. Ismail and N. H. Abdullah, "Developing electronic medical records (EMR) framework for Malaysia's public hospitals," Proceedings of the IEEE Colloq. Humanit. Sci. Eng., 2016, pp. 131136, 2011.

[31] D. Shah, and A. Bakshi, "Review on hospital management system," International Journal of Research in Science and Engineering, 1(Special Issue 1), 346-350, 2015.

[32] P. Chatzoglou, L. Fragidis, T. Doumpa, and V. P. Aggelidis, "Hospital Information System Evaluation," Proceedings of the 10th Int. Conf. Inf. Commun. Technol. Heal., pp. 240-257, 2012.

[33] C. Jenkinson, "Patients' experiences and satisfaction with health care: Results of a questionnaire study of specific aspects of care," Qual. Saf. Heal. Care, 11(4), 335-339, 2002.

[34] N. A. Mohamadali, N. Faizah, and A. Aziz, "The technology factors as barriers for sustainable Health Information Systems ( HIS ) - A review," Procedia Comput. Sci., 124, 370-378, 2018. 